Article

\title{
The Role of Transacademic Interface Managers in Transformational Sustainability Research and Education
}

\author{
Katja Brundiers *, Arnim Wiek and Braden Kay \\ School of Sustainability, Arizona State University, PO Box, 875402, Tempe, AZ 85287-5402, USA; \\ E-Mails: arnim.wiek@asu.edu (A.W.); braden.kay@asu.edu (B.K.) \\ * Author to whom correspondence should be addressed; E-Mail: katja.brundiers@asu.edu; \\ Tel.: +1-480-965-1304.
}

Received: 16 September 2013; in revised form: 22 October 2013 / Accepted: 23 October 2013 / Published: 30 October 2013

\begin{abstract}
Working towards sustainable solutions requires involving professionals and stakeholders from all sectors of society into research and teaching. This often presents a challenge to scholars at universities, as they lack capacity and time needed for negotiating different agendas, languages, competencies, and cultures among faculty, students, and stakeholders. Management approaches and quality criteria have been developed to cope with this challenge, including concepts of boundary organizations, transdisciplinary research, transition management, and interface management. However, few of these concepts present comprehensive proposals how to facilitate research with stakeholder participation while creating educational opportunities along the lifecycle of a project. The article focuses on the position of a transacademic interface manager (TIM) supporting participatory sustainability research and education efforts. We conceptualize the task portfolio of a TIM; outline the capacities a TIM needs to possess in order to successfully operate; and propose an educational approach for how to train students in becoming a TIM. For this, we review the existing literature on TIMs and present insights from empirical sustainability research and educational projects that involved TIMs in different functions. The article provides practical guidance to universities on how to organize these critical endeavors more effectively and to offer students an additional career perspective.
\end{abstract}

Keywords: interface management; sustainability pedagogy; sustainability career; sustainability education; stakeholder engagement; real-world learning 


\section{Introduction}

Transformational sustainability science develops evidence-supported solutions to sustainability challenges and trains students in this capacity [1]. Transformational sustainability science has been developed in distinction from descriptive-analytical modes of sustainability science that primarily aim at enhancing the understanding of complex human-environment systems [2]. While this might be useful, it is insufficient for providing actionable knowledge to guide societal transformations towards sustainability. Another dimension of transformational sustainability science is the extent of change necessary, which ought to be significant, not only marginal or incremental, reaching deep into the underlying structures of our society [3]. While we fully subscribe to transformational sustainability science as an aspirational goal, we consider in this article primarily the feature of generating actionable knowledge and are lenient regarding the extent of change (see the project example provided below in Box 1).

Research and teaching in transformational sustainability science involves professionals and stakeholders in different functions in order to integrate practical/local knowledge and create buy-in for the implementation of solution options [4,5]. While this is widely considered "best practice", it often presents a challenge to scholars at universities, as they lack capacity and time needed for negotiating different agendas, languages, competencies, and cultures among faculty, students, and stakeholders [6,7].

A variety of management approaches have been developed to provide support in dealing with this challenge, including concepts of the boundary organization [8-10], post-normal science and transdisciplinary research [11-13], transition management [14,15], and interface management [16]. In addition, quality criteria for participatory sustainability research provide guidance for managing interfaces between researchers and practitioners [5,17,18].

However, only fragmented ideas exist regarding the specifics of the facilitation of research with stakeholder participation while creating educational opportunities along the lifecycle of a project. There is little detail available on the role of the facilitator in this process, who serves as a transacademic interface manager (TIM). We have coined this term [6,7] in reference to the early concept of "transacademic" research in which scholars and stakeholders collaboratively conduct research, co-producing evidence [19]. The terms "transacademic" or "participatory" research are used interchangeable in this article, and do in fact represent a wider cluster of converging paradigms, including collaborative, phronetic, post-normal, issue-driven interdisciplinary, Mode-2, and transdisciplinary research [4,5,11,20-22]. Despite differences in the specific approaches, common features are that they all include non-academic stakeholders into the research (knowledge generation) process, strive for generating knowledge that is of relevance to society (context of application), encourage diversity in knowledge claims and normative stances, and therefore engage participants in processes of reflection, deliberation, and negotiation. The term "scholars" refers to researchers in faculty positions at universities who lead research teams and supervise student researchers. "Stakeholders" are defined as groups or individuals from government, business, non-profit organizations, and the public, who are affected by, cause, or have another relevant stake in the problem that is being addressed or the solution options that are being developed in the participatory research process.

As stated earlier, in this article, we go beyond the basic format of transacademic or participatory sustainability research and highlight transacademic research that actively involves students and 
therefore provides a unique educational setting [6,7,23]. We focus on the role of TIMs in such transacademic sustainability research and education projects, with special attention to the requirements that stem from the educational settings.

The goal of the study is to fully conceptualize the position of the TIM, with particular emphasis on TIM's role in educational settings. The article addresses the following guiding questions:

(1) What does TIM do in transformational sustainability research and education?

(2) What capacities does a TIM possess (in order to fulfill these tasks)?

(3) What is an appropriate pedagogy that allows students to acquire TIM capacities?

The remainder of the article is structured as follows: Section 2 reviews existing concepts about TIM across different streams of literature. Section 3 presents the tasks and activities TIM carries out over the life-cycle of a participatory sustainability research and education project, focusing on the specific educational requirements. Section 4 presents the capacities TIM needs to posses in order to successfully complete these tasks and activities. Section 5 outlines an educational program to train students in becoming TIMs.

The article offers a practice-oriented concept of the TIM as a key player in participatory sustainability research and education. As different communities of scholars and professionals have made significant progress in transacademic interface management over the past 15 years, there are quite rich experiences available that can inform the professional practice of the TIM. The compilation of TIM's tasks, capacities, and training opportunities presented in this article is based on a variety of sources: literature reviews (Section 2); research on the role of TIMs in sustainability research projects with educational opportunities at six universities [7]; and the authors' experiences from working in such projects at the Swiss Federal Institute of Technology Zurich, the University of British Columbia, Vancouver, and Arizona State University over the last 10 years, e.g., [2,4,6,13,23]. This synthesis article is intended to support universities in organizing participatory sustainability research and education more effectively and to offer students an additional career perspective.

\section{Concepts of the Transacademic Interface Manager}

This section reviews the literature on the transacademic interface manager (TIM) who manages the collaboration between scholars and stakeholders in participatory or transacademic sustainability research. Although we focus in this article on transacademic interface management in sustainability research and education $[1,2,5]$, we draw from a broader variety of literature to inform the concept of the TIM. We review five concepts of the TIM from different strands of literature. We paraphrase the concepts referencing the key terms used in the literature and later comparing the approaches regarding similarities and differences.

\subsection{Boundary Manager}

For the science-policy interface, Guston [8], Miller [9], and others have developed the concept of the boundary organization. A boundary organization is a staffed institutional arrangement that facilitates productive policy making through collaborative (research) processes between representatives of the science community and those of the policy/society community. Boundary organizations serve as 
intermediaries and play a distinctive role that would be difficult or impossible for organizations in either community to play. The literature acknowledges that in reality those communities can be internally diverse, and the boundaries can be permeable. Cash et al. [17] see boundary organizations as pivotal to recast the interactions between scholars and practitioners in order to create "integrated knowledge systems" for sustainability problem solving. Boundary or hybrid management is the process through which to achieve such a co-production of knowledge and policies [9]. A central position in this process is the boundary manager. Despite the fact that the literature on boundary organizations leaves room for interpretation on the role of hybrid managers, it seems salient to argue that this position includes the following responsibilities: ensure neutrality and reciprocal accountability as to not favoring any side and facilitating processes and results useful to both communities, including the set up and facilitation of two peer review committees [8]. Miller [9] argues that hybrid managers are mostly charged with helping project participants to take knowledge claims apart, unraveling underlying value claims (deconstruction) in order to co-construct knowledge in a collaborative way (hybridization). Hybrid managers facilitate flexibility in ways of thinking, unlock collaboration by shedding light on choices and activities, support responsiveness among participants and fair voting rules, and ensure transparency, which has shown to decrease controversies and increase effectiveness of hybridization. Active mediation is required to create processes and outcomes that are salient to stakeholders, credible in the eyes of the scholarly community, and legitimately produced [17]. Yet, even with skillful mediation, those three goals are difficult to reconcile [24].

\subsection{Boundary Spanner}

Williams [10] points out that little attention has been paid to how individual actors, i.e., boundary spanners, build relationships and successfully manage collaborative problem solving across different communities of knowledge and across different administrative and geographic scales. This is striking as research shows that boundary spanners are essential for effectiveness and success of inter- and cross-organizational ventures struggling to solve "wicked problems". Synthesizing the literature in public administration and organizational management with empirical results in the United Kingdom, Williams [11] compiles tasks and capacities for boundary spanners. His emerging framework for boundary spanners includes (i) building and sustaining relationships and networks with a wide range of actors, (ii) creating non-hierarchical environments and enabling joint decision-making through skilled negotiations and brokering, (iii) managing complexity and interdependencies of project participants by empathizing with their motives, roles, responsibilities, and accountabilities, and (iv) taking on the role of a "policy entrepreneur" to catalyze innovative solutions and mobilize resources. His research suggests that the ability to create trusting relationships and resolve conflicts constructively depends on personality traits, including, e.g., respect, honesty, openness, tolerance, approachability, reliability, and sensitivity.

\subsection{Epistemediator}

Transdisciplinary research and post-normal science address complex real-world problems by integrating perspectives, knowledge, and values of diverse expert and stakeholder groups [11,12]. The goal is to link scientific and local knowledge in order "to develop knowledge and practices that promote what is perceived to be the common good" ([12], p. 20). Reviewing frameworks for such 
knowledge integration, Guimaraes Pereira and Funtowicz [25] recognize the need for advanced facilitation and mediation between different knowledge claims and normative stances. The process is called "extended peer-review", which allows negotiating such claims across different communities of knowledge and values. Wiek ([13], p. 56) has termed the mediator of this process, an "epistemediator" who would "facilitate the (epistemic) process of joint knowledge generation, revealing and balancing standards of scientific and local knowledge". Turnpenny et al. [26] point out that this process of quality control through extended peer-review explicitly includes cultural and moral perspectives. To put the different knowledge sources on equal footing, Failing et al. [27] propose that both value-based and scientific knowledge claims have to meet quality standards, e.g., the quality of a value claim could be related to clarity, consistency and explicitness. According to de Vos Malan [28] such transdisciplinary project managers facilitate communication, knowledge integration and synthesis. This task is very challenging, as such mediators would have to "cope with a great number of social aspects such as communication technology and virtuality, team size and structure (power, roles, possibility of participation), etc. that could greatly influence the knowledge-generation performance of the collaborating agents" ([13], p. 57). This pertains in particular to contentious questions about power and influence, namely, who participates and how in decision-making [29]. Stauffacher et al. [23] present one of the few studies that use the transdisciplinary context as educational setting for problem-based case studies so that students learn about the social contract between science and society through their own practice. However, the instructor takes on a dual role of being an instructor and the TIM, which impacts on TIM's neutrality.

\subsection{Transition Manager}

Van de Kerkhof \& Wieczorek [30] initially developed the concept of a transition manager as an independent process facilitator between scientists and stakeholders in transition management. The key characteristics of this position are independence, expertise in process management and mediation, and ability to keep a good overview of important activities in the field. Loorbach and Rotmans ([14], p. 199) describe the role of the transition manager in more detail:

"There is an important role here for the transition manager, who brings together the various parties, is responsible for the overall communication in the transition arena, acts as intermediary in discordant situations, and has an overview of all the activities in the arena. The transition manager should also ensure a balanced representation of participants from business, governments, non-governmental organisations, knowledge institutions, and end-users/consumers. After some time, arena participants may be replaced by new participants with other competencies and practical orientations. The transition manager guards this substitution process carefully in order not to disturb the balance in the arena".

Loorbach [15] further develops and details the framework for transition management and expands the concepts of the transition manager. The transition manager is the key facilitator in the transition arena, which is a real and virtual space, governed by some institutions (rules), that structure and facilitate collaboration and collective action, while being conducive to innovation and transformation. Transition arenas bring together a group of frontrunners, including experts, opinion leaders, and 
gatekeepers from government, private, public, community, and academic organizations [15]. Frontrunners' are able to dissect complex problems, work collaboratively, enjoy authority within their networks, and have experience in exploring innovative and transformational solutions. Key tasks of the transition manager are to create and maintain such transition arenas. Apart from management and facilitation skills, the transition manager possesses some degree of expertise and experience in transformational sustainability research, in particular in participatory processes. These experiences could include applying a systems approach for problem structuring, experience with visioning methods, developing transition agendas with objectives, experiments, and instruments to realize these objectives, as well as evaluation. Transition research and management does not happen in a vacuum; instead, they are deeply embedded in ongoing debates and struggles of power and politics [31]. The transition manager needs to possess the capacity to read and navigate issues of power structure, contestation, conflict, partial interests, and instrumentalization. Reading and navigating these power issues requires a reflexive process, which is challenging because TIM is part of those power structures [32]).

\subsection{Interface Manager}

With emphasis on management tasks in interactive sustainability research, Robinson and Tansey [33] describe a centralized project-management team comprising of professional administrative and community outreach staff that proved to be essential to achieving overall project goals. It helped navigating the different needs, expectations, and cultures between academic researchers and stakeholders. It allowed the entire project team to engage in the collaboration while keeping to the agreed upon principles of "no net increase of work" (to avoid fatigue and burn-out) and "mutual benefit" (to ensure consistent participation). Moll and Zander [16] offer strategies to manage the interface between research and implementation for sustainable development. They provide interface managers with practical tools for teambuilding and professional project-management; stakeholder engagement that is sensitive to different groups; and effective communication with different audiences. Talwar et al. [4] draw attention to the underlying institutional structures (e.g., incentives, rewards) in which participatory sustainability research takes place. As they can be more or less supportive, they can have a major influence on the task portfolio and activities of an interface manager.

\subsection{Similarities and Differences among TIM Approaches}

There are even more concepts of interface managers [34]; yet, the review of the described concepts already indicates robust convergence on the following TIM features. First, the need for a TIM arises from the widely acknowledged challenges of collaborations across different communities of knowledge and values. Such collaborations demand bridging different worldviews, ways of knowing, motivations, interests, and power positions, which often are incommensurable or even conflicting. In addition, practical aspects strain the collaboration, namely time constraints, mandates and rewards, as well as individual capacities and skill levels. A TIM is being described as an individual or an entire organization with different task portfolios and capacities to cope with these challenges. The dynamic of participatory research processes requires that TIM flexibly adopt the set of activities and support structures most appropriate to the respective stage of the process [35]. Second, it is being recognized that while project management is a key task, TIM is more than a coordinator and facilitator. This is due 
to the expectation that TIM ought to enable collaboration among different knowledge communities in order to co-produce actionable knowledge and to enable social learning for sustainability [36]. Third, commonly mentioned activities that TIM ought to execute include: initializing and maintaining a functional and continuous process of collaboration; creating and maintaining mutual ownership and accountability among project participants; integrating knowledge and reinforcing a solution-oriented perspective; facilitating constructive communication and mediating tensions and conflicts. Fourth, the literature convergences on some key capacities TIM ought to possess, in particular interpersonal competence, including empathy, communication and negotiation skills, and some level of expertise in participatory research approaches. In addition, it is advantageous for a TIM to posses some level of strategic competence, including expertise in strategy building, an entrepreneurial mindset, knowledge about transformational processes (e.g., key strategies, common barriers, resources) and political competence (identifying power structures, ability to create spaces of democratic inquiry).

However, different viewpoints exist regarding some key features of TIM. The majority of contributions call for a TIM as an independent, neutral, third-party person or unit with experience in both research and action/policy-/decision-making [36]. Some propose instead "actors in science" as candidates for the TIM position [16]. Pielke, Jr. [37] defines a TIM as an "honest broker", and suggests that this is the adequate role of scientists engaged in science-policy interactions. The honest broker combines two roles, one being a scientist and the other being a moderator. This helps avoid issues of advocacy or the risk of politicizing science in the pursuit of special interests. The risk of this combined approach is that it requires academics to take on the role of TIM on top of their primary role of conducting and supervising research for the project and educating students. This is burdensome and challenging as few scholars are trained in interpersonal and mediation skills or work in environments that build such expertise "on the job" [28]. Additionally, the double role of an honest broker might lead to perceived or real conflicts of interest.

Table 1 below, provides an overview of TIM features as extracted from the different domains of literature.

Attitudes of TIM commonly include approachability, reliability, sensitivity, honesty, openness, tolerance, and an entrepreneurial spirit. These attitudes help to establish trust, which is particularly important for TIM when mediating issues of authority, power, rights to participate, and decision-making rules.

With few exceptions, such as Stauffacher et al. [23], none of the reviewed streams of literature address TIM's role in educational settings, or how to train a TIM. This is, however, the focus of the present article.

Table 1. Features of a transacademic interface manager (TIM) in various domains of literature.

\begin{tabular}{l|l}
\hline $\begin{array}{c}\text { Domain of literature } \\
\text { Institutional arrangement } \\
\text { Name for TIM }\end{array}$ & \multicolumn{1}{c}{ Complementarities and differences of role } \\
\hline - Science-policy studies & $\begin{array}{l}\text { Neutral convener. } \\
\text { Facilitates "hybridization" of knowledge- and value-claims } \\
\text { for policymaking between science and policy/society } \\
\text { - Boundary organization }\end{array}$ \\
- Boundary manager & $\begin{array}{l}\text { Creates institutions to equally account for interests of both } \\
\text { communities: enabling choice, two peer committees, } \\
\text { decision-making rules, mediation. }\end{array}$ \\
\hline
\end{tabular}


Table 1. Cont.

\begin{tabular}{|c|c|}
\hline $\begin{array}{c}\text { Domain of literature } \\
\text { Institutional arrangement } \\
\text { Name for TIM }\end{array}$ & Complementarities and differences of role \\
\hline $\begin{array}{l}\text { - Public administration } \\
\text { - Inter-organizational networks } \\
\text { - Boundary spanner }\end{array}$ & $\begin{array}{l}\text { Establishes relationships with actors within or across an } \\
\text { organization to bring them into a new network to support } \\
\text { policy making (science or knowledge creation not at focus); } \\
\text { Facilitates collaboration through engaging bilateral } \\
\text { relationships, brokering, and conflict resolution. }\end{array}$ \\
\hline $\begin{array}{l}\text { - Transdisciplinary research; } \\
\text { Post-normal science } \\
\text { - Extended peer review } \\
\text { - Epistemediator; Transdisciplinary } \\
\text { project manager }\end{array}$ & $\begin{array}{l}\text { Supports the science-society interface in research and } \\
\text { education. } \\
\text { Facilitates integration of knowledge-and value-claims to } \\
\text { co-create novel knowledge, e.g., convenes and supports } \\
\text { extended-peer reviews and facilitates collaborative research } \\
\text { processes. }\end{array}$ \\
\hline $\begin{array}{l}\text { - Transition management } \\
\text { - Transition arena } \\
\text { - Transition manager }\end{array}$ & $\begin{array}{l}\text { Creates network of change agents. } \\
\text { Facilitates implementation of a transition process, not just } \\
\text { collaboration on a project. }\end{array}$ \\
\hline $\begin{array}{l}\text { - Transformational sustainability } \\
\text { research } \\
\text { - Collaborative project } \\
\text { - Project-management team; } \\
\text { Interface manager }\end{array}$ & $\begin{array}{l}\text { Facilitates participatory and interactive research activities } \\
\text { and collaboration between scholars and stakeholders, as } \\
\text { part of a project focused on actionable sustainability } \\
\text { knowledge. }\end{array}$ \\
\hline
\end{tabular}

\section{What Does a TIM Do?}

The previous literature review suggests convergence on TIM being an essential part in participatory sustainability research projects. To achieve the ambitious goal of facilitating a collaborative process that yields solutions to sustainability problems, TIM adopts various roles of a facilitator, mediator, translator, and process innovator. However, the literature offers little with respect to educational opportunities in sustainability research projects, or the education of TIMs-despite the increasing number of sustainability projects that integrate research and teaching [5,7,38]. Also, there is little practice-oriented guidance articulating when TIM is doing what along the lifecycle of a project. Thus, this section conceptualizes the activities of TIM along the lifecycle of participatory sustainability research projects with educational opportunities. We illustrate the concept with a project that integrated participatory sustainability research and teaching on neighborhood sustainability in Phoenix, Arizona (Box 1, and examples throughout this section).

Participatory sustainability research projects with educational opportunities allow faculty, students, and stakeholders to collaborate on solutions to real-world sustainability challenges. They provide a professional learning environment for students and offer opportunities for capacity building among all parties involved. Such projects are typically structured into five phases: (1) preparing the project; (2) orienting and framing the research (research proposal); (3) doing the research; and (4) evaluating the implementation of the solution (Figure 1). If these projects are carried out as a course for students, they often only entail the two core phases (Phases 2 and 3), preceded by pre-course preparations and 
followed by post-course extension activities [4,39]. Participatory sustainability research projects with educational opportunities differ from participatory sustainability research projects in a few aspects. First, they have to strike a balance of producing meaningful learning and research outcomes, as well as outcomes relevant to stakeholders. Second, TIM's role expands towards coaching students in conducting participatory research. Lastly, they are usually funded through internal university and local supplementary funds, as opposed to conventional external funding of research.

Box 1. Project profile of integrated participatory sustainability research and teaching on neighborhood sustainability in Phoenix, Arizona [40].

Trees and Shade for the Sky Harbor Neighborhood in Phoenix, Arizona

The School of Sustainability at Arizona State University has been working with the Sky Harbor Neighborhood since 2009. However, most of the early projects benefitted students more than the neighborhood. Hence, the neighborhood association was reluctant to engage in a new collaboration in late 2011. Two faculty and a TIM from the School of Sustainability spent time to learn about the past experiences, unfulfilled promises, and future expectations from community members. Together, they developed an agreement for collaboration on a project to address the lack of trees and shade in the neighborhood. The Sky Harbor Neighborhood has historically been neglected by planning and economic development, leaving the neighborhood with little walking infrastructure and public amenities. The project objectives were to develop an evidence-supported strategy for increasing tree coverage and shade in the neighborhood, and to support the neighborhood in the implementation process. The outcomes of the project included an intervention manual, which was peer-reviewed by the neighborhood association, city planners, and other experts; creating buy-in across all relevant constituencies for the implementation phase; funding for planting trees; an academic publication [40]; and enhanced capacity for intervention and implementation research among the participating students. The project was carried out during the Spring 2012 term. The project team included four graduate students and one undergraduate student.

Project meetings occur in each phase of the project and build a critical element in TIM's activities portfolio. Because of their recurring character, we briefly describe the key meeting features here in advance, before detailing TIM's activities in each phase. Project meetings build important milestones of the projects as they bring the core team together (faculty, students, partnering stakeholders), open/close each phase, and critically review work in progress. These meetings are pivotal decision-points of the entire project and require TIM's full attention to gathering information (e.g., create agenda and pool inputs from all parties), facilitation (e.g., use visuals to support translation and integration of critical issues, ask clarifying questions, offer choices), and follow-up (e.g., draft memo, check-in with participants to monitor action items, plan next steps). 
Figure 1. Overview of TIM's activities along the lifecycle of participatory sustainability research projects.

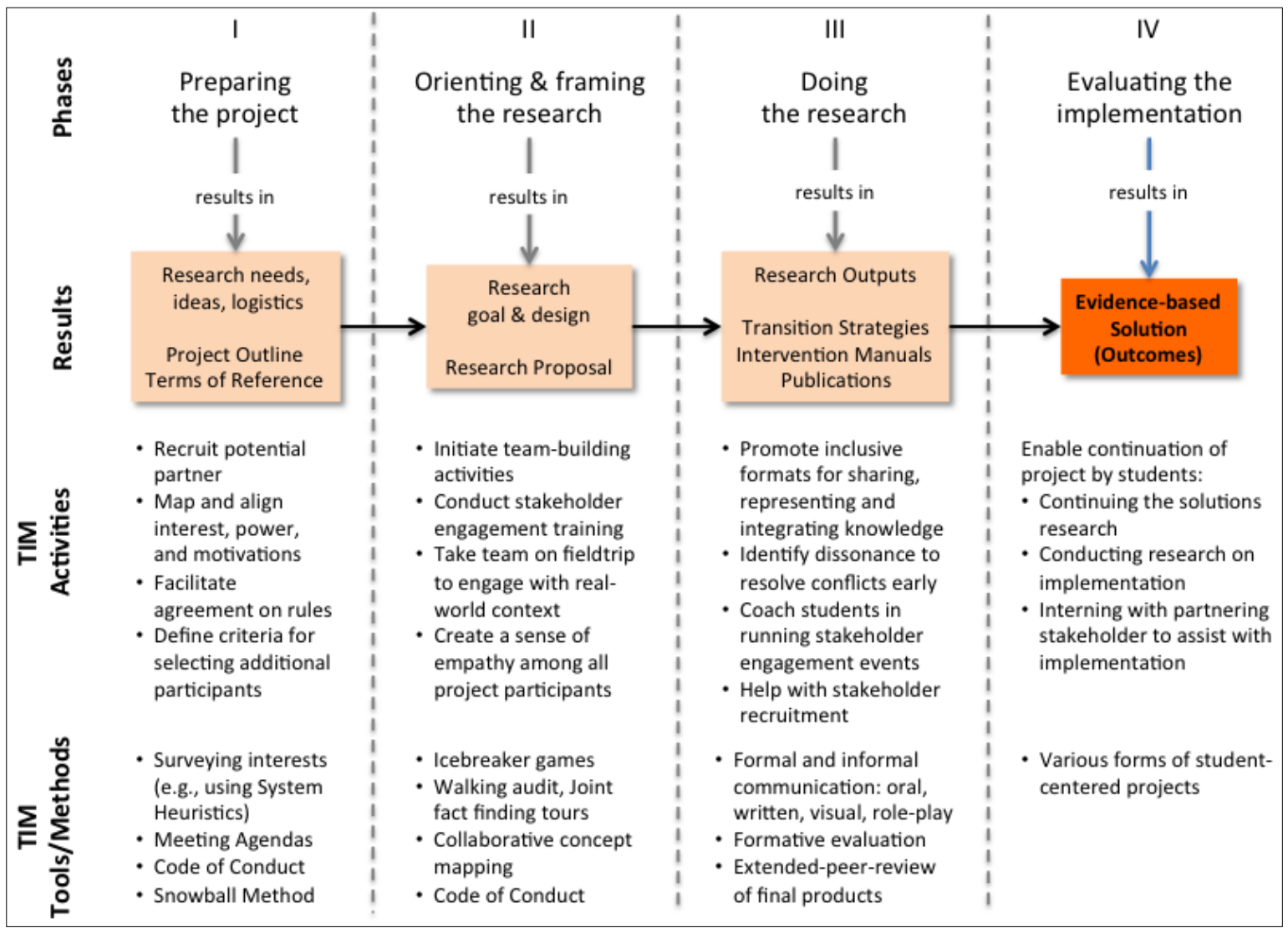

Another important issue concerns the phase when students enter the project. In principle, they can be part of the project from the beginning (Phase 1). However, because of semester schedules and other logistical challenges, students might only participate as of Phase 2. Similarly, there might be logistical and other reasons for completely setting the stage for the project (Phases 1-3) without student involvement. In these cases, students might only participate as of Phase 4. We describe the phases below with student involvement.

\subsection{Phase 1: Preparation-Eliciting Inputs and Creating a Frame of Reference}

Phase 1 is the preparation phase, which explores interests and feasibility of project ideas $[5,41]$. As a first step, TIM elicits research needs and project ideas from stakeholders, faculty, or students through informal and formal communication. The goal is to create a pool of potential sustainability research needs and project ideas. TIM informally initiates or enters several conversations and sounds out what sustainability issues are being discussed. This includes monitoring local developments through reading newspapers, attending public meetings, maintaining a network of informal contacts, and staying tuned with faculty's research and course offerings. Additionally, stakeholders might approach TIM directly with research requests. Formal approaches streamline the acquisition of projects through a request-for-proposals issued by the university to which stakeholders respond in sync with the university's course planning process. 
As a next step, TIM matches stakeholder's interests with course offerings and research streams at the university to identify the best fits. Thereby, TIM needs to carefully explore how a project could be carried out to the mutual benefit of stakeholders (addressing their interests), scholars (contributing to ongoing research), and students (enabling rich learning experiences). It is a challenging task to create such win-win-win constellations. Mismatches can lead to lower educational attainment, damaged relationships, and personal frustration. Thoughtfully mapping out expectations and interests as well as carefully deliberating convergence and divergence are early success factors for the project.

Transacademic educational research projects come in all shapes and forms, including small in-class projects complementing a course, internships, thesis projects, or entire 1-2 semester long research studio courses $[6,7,39,42]$. This article focuses on semester-long research studio courses. TIM drafts project vignettes outlining in general terms the research rationale (research idea, relevance), potential participants, logistics (timelines, budget), and pedagogies. Suitable pedagogical approaches draw on project- and problem-based learning [39], which faculty and stakeholders are often less familiar with.

Lastly, TIM pitches these ideas to stakeholders, faculty, and students to recruit them to a first meeting with the goal of securing commitment to the project. Such a pitch points out the value add for all parties to be involved, but also clarifies the rationale of such a studio course (capacity building, not consultancy work; transformational purpose, not service learning). If the potential partnering stakeholders agree to collaborate, TIM uses the meeting and bilateral conversations to specify expectations and project objectives, unearthing underlying concerns or requirements for successful collaboration, and sharing an outline for the project logistics (timeline, budget, equipment). TIM facilitates the forming of a leadership team between faculty (course instructors), students, and partnering stakeholders, and clarification of their roles and responsibilities as well as mechanisms for shared accountability. In planning the project and timing of contributions, TIM encourages the leadership team to develop realistic expectations, acknowledging, that team members have other responsibilities than to the project [43]. In the process of fine-tuning the project, TIM supports the leadership team to anticipate the different project phases as well as how and when the project partners envision using and implementing the results. Anticipating how the course should evolve and to what ends, helps TIM to understand what support the leadership team needs along the whole process. An intact working relationship between TIM and the course instructor is essential for success. TIM supports the instructor in negotiating and collaborating with stakeholders, as well as in developing appropriate course designs to build professional competence in students. In exchange, instructors need to be open to this support by delegating part of their responsibilities and power to TIM.

Table 2 provides an overview of the support needs for partnering stakeholders, faculty, and students most commonly encountered in participatory sustainability projects.

TIM helps to provide this support, or facilitates the support delivery by recruiting internal or external experts. For instance, TIM works with partnering stakeholders to define suitable ways of communication and help them prepare for visits to class. It is key that TIM starts early to explain to everybody involved how researchers, students, and professionals respectively operate, and invite project participants to share their work environment and culture. Building this mutual understanding is key to a successful collaboration.

At the end of Phase 1, the leadership team has developed an agreed-upon project outline that defines an initial frame of reference for the next stage, and includes the timeline, organizational chart, 
budget, and terms of reference (e.g., in form of a letter of agreement, contract, or MOU). This outline is not the research proposal, which will be the result of activities in Phase 2.

Table 2. Support activities provided by TIM during the preparation phase.

\begin{tabular}{|c|c|c|}
\hline Support for partnering stakeholders & Support for faculty & Support for students \\
\hline $\begin{array}{l}\text { Facilitate understanding of course } \\
\text { design and assist in critical review } \\
\text { of syllabus; } \\
\text { Making sure important events and } \\
\text { deadlines are on their agendas; } \\
\text { Brief about visits to class: what to } \\
\text { expect, how to prep; } \\
\text { Defining suitable ways of } \\
\text { communication }\end{array}$ & $\begin{array}{l}\text { Contributing ideas and } \\
\text { assistance for pedagogy; } \\
\text { Accounting for needs and } \\
\text { perspective of partnering } \\
\text { stakeholders; } \\
\text { Facilitating review of } \\
\text { syllabus through partnering } \\
\text { stakeholders; } \\
\text { Coordinating logistics, } \\
\text { meetings, communication }\end{array}$ & $\begin{array}{l}\text { Prepare activities and material for } \\
\text { training sessions on teamwork } \\
\text { and stakeholder engagement; } \\
\text { Prepare forms (e.g., liability } \\
\text { waivers for fieldtrips, application } \\
\text { for ethics approval of research); } \\
\text { Set up virtual collaborative } \\
\text { spaces and tools }\end{array}$ \\
\hline
\end{tabular}

\subsection{Phase 2: Orienting and Framing the Research (Research Proposal)}

Phase 2 is the orienting and framing phase, which is about jointly setting the research objective and creating a research design $[5,44]$. The studio course usually starts with Phase 2 .

With the start of the course, TIM visits the course to be introduced to the students (if they have not been involved in Phase 1). The goal is that students recognize TIM as their contact person who supports them in managing interfaces, which includes the interactions with the course instructor(s), with partnering and other stakeholders, and within the student teams. TIM introduces the organizational chart of the course and the broader social network of the project to give students a first sense of who is involved, in what roles, and with what interests. TIM facilitates a discussion about the various perspectives and power-relations, and how students plan to manage expectations. This meeting kicks-off a series of activities for students related to teamwork and participatory research.

TIM initializes working relationships with those students who are assigned the role of "Stakeholder Contact". The idea is that students step into the line-up of relations with stakeholders, while TIM guides from the sides. Although this is a critical learning objective for all or most of the students, it is a challenging undertaking which requires practicing caution, in particular if the project addresses sensitive or controversial sustainability issues (e.g., radioactive waste disposal; superfund site cleanup; illegal immigration). Therefore, adequate training is critical. Initial training activities include a meeting between TIM and students to review a stakeholder participation matrix, where students explain why and how they plan to involve stakeholders in the project and how they organize the first contact (e.g., join a neighborhood association meeting, volunteer at community event relevant for stakeholder, set up special meeting time). Students engage in role-plays to explore common challenges that these encounters could pose: e.g., a stakeholder has shifted or lost interest, or forgot the meeting. Depending on the situation, TIM introduces stakeholders and students virtually or accompanies students to meetings.

Based on the project outline, TIM supports faculty, students, and partnering stakeholders in specifying the problem to be addressed (framing it as a sustainability problem), the solution space, and different research designs. For this, TIM organizes and facilitates one or more structured, workshop-style 
discussions to identify converging/diverging perspectives and create agreement. Additional tools are Walking Audits or Joint Fact Finding Tours that provide experiential or in-depth knowledge about the problem to be addressed or possible solution spaces. TIM supports faculty, students, and partnering stakeholders in preparing those events and joins the events, too. TIM also helps the leadership team to develop agreement on a functional and robust research design that can deliver on the aspired project outcomes (solution to sustainable problem). Details on appropriate research designs can be found in $[1,4,44]$. Brundiers and Wiek [6] highlight key challenges of this process, for instance, the collaborative identification of problems as sustainability problems. These are challenge areas for TIM to look out for and provide special assistance (e.g., using visuals and hands-on-activities to map out the problem/solution space, engage in bilateral conversation and propose options how to reconcile the issue).

As the research proposal emerges, TIM anticipates what the practical implications could be for stakeholders, faculty, and students. TIM engages the leadership team in carefully assessing these (and identifying potential other) implications and developing precautionary measures. For example: How do students travel to the community and what are the budget requirements? How and when do students enter the community and how can they get access to gate-keepers? If the research design foresees, for example, door-to-door interviews, will this put students at risk, require a translator due to language barriers, or cause stress on communities (e.g., undocumented community members)?

To prepare the actual research in Phase 3, TIM checks in with faculty and students to identify specifically what support they might need from TIM when starting their research. If students plan workshops as part of their data collection and interpretation activities, then TIM works with them to define the dates for these workshops, to check availability of locations, to get the word out in the community (save the date), and to recruit event participants.

To close the orienting and framing phase, TIM facilitates a review meeting between students, instructors and partnering stakeholders to generate agreement on the research proposal, detailing the sustainability problem to be addressed, project goals, and research design.

\subsection{Phase 3: Doing the Research}

In Phase 3 the project team implements the research proposal. Students collect and analyze data, interpret it and synthesize the findings in collaboration with stakeholders and faculty. However, adjustments might be necessary due to insights gained over the course of the project. The goal of this phase is to generate "actionable knowledge", that is, knowledge than can mitigate or solve the problem addressed (which triggered the project in the first place).

TIM monitors the process and is available if needed. Monitoring activities include checking in informally with each party to sound out what support is needed. Towards the end of the course, students are increasingly stressed. Having less energy, they often feel frustrated as much remains to be done in little time, facing other common challenges such as tensions in the team, unexpected changes to stakeholder engagements, and feedback on preliminary outputs requiring additional revisions. Keeping students situation in mind, TIM intervenes if necessary to help renegotiate expectations among students, instructors and partnering stakeholders.

Throughout Phase 3, TIM works closely with the "stakeholder contact" students to identify needs (e.g., group has difficulty recruiting stakeholder for participatory events; or group struggles with 
eliciting meaningful feedback from stakeholders) and issues (e.g., group is discouraged by feedback from stakeholder). TIM tries to resolve those issues timely, by working with the student team, with the stakeholders, or mediating a joint meeting.

TIM also supports the project team in preparing stakeholder engagements (e.g., workshops, satellite events) in a timely manner. TIM knows that these events take always more time than students have budgeted, which negatively affects their motivation. Leading up to the actual event, students draft a stakeholder engagement guide, which serves the role of a guidebook. TIM reviews this document adopting the perspective of the event participants, which can include a wider range of residents (e.g., families, elderly, single mothers, immigrants), city staff (city planner, police officers), representatives of business councils, advocacy groups, and so forth. With these perspectives in mind, TIM focuses on the recruitment for the event, the length of the engagement, and the flow of activities. TIM considers questions including: Are all relevant stakeholders invited? Are the most effective recruitment strategies employed? Are the activities appropriate for the capacities of participants? Are activities well explained and engaging (e.g., use of visuals)? Does the event require translators, babysitters, and/or photographers? Critical is to make an honest assessment of time needs, and try to keep activities dense in order to respect participants' time. Usually, instructors and partnering stakeholders review the guide related to research and project needs respectively. Once the Stakeholder Engagement Guide is revised, TIM attends students' dry-run: the mock-stakeholder event, which helps students learn their roles, test the material in action, and engage in role-plays with stakeholders. In addition to being rehearsals, these dry-runs help students to anticipate and mentally prepare for the eventualities of the event.

TIM supports the project team well in advance to prepare for the final project presentation where the project team shares the results of the project and insights into its process in appropriate and engaging ways. TIM supports the project team to make sure that all relevant stakeholders attend the final presentation. The final presentation fulfills multiple purposes. It can help students in receiving realistic feedback from stakeholders such as city officials; or it can expose scholars to new pedagogical approaches; it can also foster the implementation process if funders and additional stakeholders are made aware of the solution options developed.

\subsection{Phase 4: Transitioning to Implementation and Post-Course Extension}

While the course comes to an end, TIM explores with the leadership team potential post-course extension activities, e.g., conducting evaluation research on implementation $[45,46]$. To this end, TIM works with the partnering stakeholders to learn how they plan on utilizing results or moving forward with the project and how students might be able to participate in those options. For example, students conduct thesis research on specific aspects (e.g., evaluating use of an intervention manual) or another studio course tests the applicability of the results in other contexts (e.g., applying the intervention manual to other neighborhoods of the city); or one of the partnering stakeholders takes on a student as intern to assist with the practical aspects of bringing the project to fruition.

TIM works with the course instructor to wrap up the course in three areas pertaining to transacademic research. First, TIM supports students to conduct extended peer-review of final products (e.g., research report, outreach material). Second, TIM brings in a graphic designer/editor to target the 
product to stakeholder audiences. Professional presentation of the results provides the instructors and students with a critical aid that often convinces scholars, administrators, future collaborators, and students of the value of this educational experience. This activity needs to be planned and budgeted from the outset, as experience shows that students do neither have the time nor the capacity for this task [7]. Third, TIM facilitates a collaborative evaluation of the transacademic and collaborative components of the course and students' professional performance to equally include the stakeholders' point of view. As part of this evaluation, TIM elicits stakeholders' additional research needs and how they could be dealt with through post-course extension activities.

Finally, TIM ensures that the course is documented and the documentation is made available for others to learn from (institutional memory). TIM keeps a record of the course material and all contacts. TIM also records testimonies from all parties to establish a full documentation for the project [43].

\section{What Capacities Does TIM Possess?}

After having outlined the key tasks and activities of TIM over the lifecycle of a sustainability project, we now review the underlying capacities TIM needs to possess to successfully execute these tasks and activities. This section summarizes the aspired capacities as learning objectives and thus serves as a "stepping stone" to the next section on how to train students to become a TIM. To this end, the previously mentioned activities and tasks of TIM are clustered into four domains of activities and related capacities.

(1) Capacity to create projects (Phases 1 and 4);

(2) Capacity to initiate contact and maintain good collaboration among stakeholders, faculty, and students (for initiating contact: Phases 1 and 2; for maintaining collaboration: Phases 3-4);

(3) Capacity to coach students (as well as faculty and partnering stakeholders) on stakeholder engagement, teamwork, and self-directed learning (Phases 2-4);

(4) Capacity to manage projects, in particular with respect to the capacity to plan, execute, and support the project (all phases) and to evaluate process, output, and outcomes (all phases, mostly Phase 4).

Evidently, finding a TIM that possesses all capacities is difficult. Hence, it might be practical for the recruitment process to think of TIM either as a team, or to ensure that TIM partners with other staff possessing the required capacities.

\subsection{Capacity to Create Projects}

Sustainability literacy and familiarity with the cultures of academia and the "real-world" help TIM to meaningfully follow the conversations in scholarly and stakeholder communities. For example, TIM needs to compassionately listen to concerns about local crimes with neighbors, while being able to discuss issues about data reliability, or correlation vs. causation with the city's neighborhood services department. Combining these skills with visionary and entrepreneurial capacities helps TIM evaluating how sustainability challenges and solution options could align with academic research at the university, practical needs in the community, and offer valuable learning experiences for students [10]. An attitude of accountability towards students, stakeholders, and instructors helps TIM to remain 
neutral in this process, considering the interests of all $[6,8,36]$. Capacities in curriculum and course development complemented with creativity in finding ways to overcome perceived and real constraints enable TIM to successfully pitch projects that resonate with scholars and partnering stakeholders [28].

\subsection{Capacity to Initiate Contacts and Maintain Good Collaboration among Project Participants}

For TIM to succeed in these activities, interpersonal competence and expertise with transacademic and community-based research approaches are important. TIM has a capacity to connect with people and connect them with each other, while being cognizant of power asymmetries. Drawing on abilities of being an active listener, attentive observer, and bridge-builder among all parties, TIM builds trusting relationships. Additionally, TIM uses informal opportunities to meet and chat with faculty, students, and partnering stakeholders to get a better sense of their interests and preferences. Thereby, TIM practices empathy with students, stakeholders, and scholars, to develop better insights about their respective circumstances and realities [47]. This helps TIM to deduce reasonable assumptions about the respective capacities of students, faculty, and stakeholders and to plan for stakeholder-student interactions. For instance, when TIM helps design a workshop that aims at eliciting and integrating knowledge, it is important to identify and build on participants' capacities as well as making power relations transparent and part of the discussion. This contributes to facilitating an atmosphere of democratic inquiry where people feel enabled rather than overwhelmed by tasks, jargon, or pace [48]. TIM also has professional capacities such as the ability to prepare and facilitate productive meetings across all parties involved and intuition and tact how to address power relations in a sensitive way.

\subsection{Capacity to Coach Project Participants on Stakeholder Engagement and Teamwork}

Interpersonal competence is core for this cluster of activities. To design the just-in-time learning activities for students, TIM draws on formal and tacit knowledge about stakeholder engagement, teamwork, and self-directed learning (e.g., concepts, activities, tools). Success hinges on TIM's capacity to identify the moment, when an intervention is timely. For instance, knowing about the theory of different stages of teamwork helps TIM to identify what situation a team is in and prepare an appropriate activity (e.g., engage students in a teambuilding activity prior to facilitating a conflict resolution process about team members who underperformed at a stakeholder meeting). Any intervention will be more productive, when TIM maintains constant, effective, empathic communication with all three parties and other people involved in the course project. Lastly, coaching means different things to students, faculty, and stakeholders. In coaching students, TIM enables students to learn about and apply skills trained on earlier in the process. Coaching faculty and stakeholders respectively means that TIM conveys the basic ideas of stakeholder engagement to ensure a shared understanding and assists them in supporting the project's process.

\subsection{Capacity to Manage Projects}

The capacity to manage projects draws mostly on interpersonal and professional skills. Specifically, TIM's ability to identify tasks and milestones that need to be achieved to accomplish the project 
outcomes, back-cast strategies how to achieve them, and account for possible barriers, or unintended consequences. TIM serves as a reliable and responsive person, capable of following a tight and dynamic project schedule. While TIM is able to adapt to surprise and develop alternative strategies, TIM is well organized, documenting the process (e.g., meeting memos) and managing the resources, including budget, logistical infrastructure, and networks (participating experts and stakeholders). Evaluation is an important element of project management. TIM is adept in monitoring the process and creating a learning organization by facilitating formative evaluations (e.g., debriefings with students after dry-runs or actual stakeholder engagements) as well as summative evaluations (e.g., mediating joint evaluation among students, instructors, and stakeholders). Since these projects are transacademic projects focused on research and education, the capacity to manage projects relies on the capacity to design research and educational experiences $[16,23,28,48]$.

\section{How Does One Become a TIM?}

This section, finally, outlines an educational program that allows students to acquire the capacities and skills necessary to fulfill the tasks and activities of a TIM in transformational sustainability research and education projects. The literature calls for the TIM being perceived as a professional career: "The 'new contract' for science and engineering that is being called for in many sustainability discussions thus needs to be seen as a truly radical contract, not just for individual studies or projects, but for whole professional careers" ([17], p. 8090). Based on these promises, sustainability students and junior faculty are demanding better preparation in order to cope with the challenges of conducting and/or facilitating high-quality transacademic sustainability research [49].

Developing an educational program is one of the main factors in establishing a new professional career track. To outline a program, we draw on the experiences with initial training modules at the School of Sustainability at Arizona State University [39]. There are two basic types of training modules: learning from projects and learning through projects.

\subsection{Learning about the Role of a TIM from Transacademic Sustainability Projects}

To illustrate this mode of learning, we draw on a graduate course at the School of Sustainability that addresses stakeholder engagement in sustainability research projects and the role of TIM facilitating such transacademic collaboration. The training module consists of students analyzing empirical case studies of transacademic sustainability research projects and identifying the activities and responsibilities of TIM. Next, they develop a proposal for a transacademic sustainability research project. The proposal also outlines the appropriate team constellation for the research endeavor. Students explain why a project requires a TIM and what TIM's tasks would include. At a later stage of the course, a TIM shares insights with students about his/her work. Additionally, students shadow a TIM in action. The learning outcomes of these activities relate to comprehending and analyzing the role and capacities of TIM as outlined in sections 3 and 4, above. Specifically, students are able to identify, describe and evaluate what tasks TIM performed; what supporting tools TIM used; how effectively tasks were carried out; and what capacities, skills, and attitudes TIM possesses. 


\subsection{Learning the Role of a TIM through Participation in Projects}

To illustrate this mode of learning, we draw on a studio-course at the School of Sustainability (see Box 1, above). The training modules here consist of role-plays and doing the actual work of a TIM. The role-plays allow all students to practice the role of TIM in the classroom. In the role-plays, students apply what they have previously learned about TIM in a simulated real-world situation. These situations address the phases and key activities along the lifecycle of a transacademic research project (Figure 1). For instance, one situation asks TIM to create a project; or to support partnering stakeholders, students, and instructors in finding a shared understanding how to frame the research project. As for doing the actual work of TIM, those students who take on the role of the stakeholder-contact and/or participate in the leadership team come closest to acting as a TIM themselves. Yet, all students have the opportunity to learn from the TIM that supports their studio-course. The learning outcomes of these modules relate to applying, analyzing, and evaluating the capacities related to creating and managing projects. In this regard, students are able to apply the role of a TIM in simulated or real processes; to critically evaluate own and peers performance as TIM; and to formulate strategies how they can further develop their capacities in this studio-course.

\subsection{Learning the Role of TIM through Designing and Carrying out Projects}

To illustrate this mode of learning, we draw on a two-semester project design and management course at the School of Sustainability. This course enrolled graduate students (2 semesters) and undergraduate students ( 1 semester). In the first semester, each graduate student identifies partnering stakeholders and co-creates a transacademic sustainability research project suitable for a team of undergraduate students. On this basis, graduate students prepare for the second semester, where they work as a TIM for undergraduate students who do the project. In this preparation phase, graduate students critically reflect on their previous experiences of learning about TIM in order to create appropriate lesson plans and activities for the undergraduate students. To cope with the challenge of being a TIM and mentoring their team of undergraduate students, graduate students engage in regular supervision activities with their peers and faculty supervisor. The learning outcomes for graduate students are to "role-model" the TIM to undergraduate students. This means, graduate students demonstrate a moderate level of competence across all areas of capacities, starting from creating a transacademic sustainability research project, to initiating and maintaining good collaboration among project participants, coaching students and partnering stakeholders in their interactions, and managing the project to achieve the jointly agreed upon outputs and outcomes. Specifically, with respect to the coaching capacities, graduate students are able to support undergraduate students in learning how to professionally and confidently engage with stakeholders.

\section{Discussion}

The proposed TIM training is an initial attempt and needs to be built out further. As our experience is based on initial experiments and reflections, various aspects warrant further attention: How to operationalize TIM's capacities in measurable learning objectives? How to formalize suitable learning activities into small stand-alone modules, and ensure they build progressively upon each other? 
And, how to ensure that TIM's role creates a space for democratic inquiry? Additionally, the institutional structures need to support the educational design. TIMs do not just get trained in one or two courses, and then perform as a professional TIM. Ideally, the university has an approach for continuous and advanced training of TIMs, from undergraduate student to graduate, and even further to staff, with the understanding that fulfilling the role of the TIM can be a career-long pursuit $[4,30]$. Three concrete actions could help this institutional development.

Collect evidence on the role of TIM for transacademic sustainability research projects. There exists mostly anecdotal evidence on the benefits a TIM provides, or on the project shortcomings in the absence of a TIM. For instance, the Australian Council of Learned Academies concluded a large interdisciplinary project aimed at addressing sustainability challenges by asserting that an "emerging group of trans-disciplinary project managers" were essential in making those projects flourish [28]. Research indirectly speaks to the benefits that TIM provides by identifying shortcomings if projects forgo a TIM. For example, stakeholders often withdraw from projects because they perceive their knowledge is not adequately represented or considered; which, in return, leads to missed opportunities for social learning [25]. Other examples pertain to project failures that arise from power and decision structures that often remain unaddressed or lack proper negotiation [36]. Often, project-initiator-turned-project-leaders are not impartial to either community and lack the capacity to manage transacademic research [5,50]. Also, students and faculty often withdraw from transacademic collaboration if they perceive their additional efforts of coordination and translation is too demanding and distracting from their main obligations [6]. Lastly, it is important to critically reflect not only on the benefits, but also on potential drawbacks of TIM's involvement in participatory sustainability research projects with educational opportunities. Potential drawbacks can result from TIM failing to be impartial, or burning bridges to critical stakeholders, or overstepping his/her competence in course instruction.

Formalizing procedures and creating mechanisms that facilitate project development. TIM's work at the university-community interface is challenged by academic calendars and course scheduling procedures that dictate pace and timing of creating and running educational research projects. To ensure a successful training program, it is important to institute an annual schedule for the lifecycle of a project that aligns with the university's course scheduling procedures. This ensures an ongoing and smooth influx of projects. To support learning from projects, it is useful to create a list with TIMs, researchers, and stakeholders, who are willing to come to class to share their experience, or have students shadowing them. All these efforts come at some cost. Budgets of such projects include TIM's work (this might even require a full position or an entire team, depending on the number of projects managed), temporary student workers to professionalize the products, expenses for students' travel, refreshments at stakeholder engagement events, small stipends for participating faculty, and so forth. One options is to feed a fund through a range of sources, e.g., partnering stakeholders' contributions, small student fees, and a direct contribution from the university. Another option is for universities to fund such project expenses entirely through the regular budget. Evidently, institutionalizing the role of TIM is always shaped by the specific context of the respective university (e.g., history, commitment, funding, teaching philosophy).

Acknowledging the spectrum of interface management needs on-campus and beyond. This article focuses on the collaboration across the university-community interface, zooming into TIM's role in 
educational transacademic sustainability research projects. Hereby, TIM can provide this role as employee of different academic units: at colleges offering such collaborative educational experiences; at universities that sustain a living learning laboratory to advance the university's sustainability by integrating education, facilities and operations, and research; and finally at boundary organizations linking university research with policy-makers. However, the university-community interface is just one among many. William's [10] asserts the wealth of interfaces that arise beyond the university as people across the society strive to tackle sustainability challenges.

"Strategic alliances, joint working arrangements, networks, partnerships and many other forms of collaboration across sectoral and organizational boundaries currently proliferate across the policy landscape. However, the discourse is positioned at an institutional and organizational level, and comparatively little attention is accorded to the pivotal role of individual actors in the management of inter-organizational relationships" ([10], p. 103).

Therefore, developing a training program for TIM and promoting interface management as a professional career requires accounting for the richness of interfaces beyond the university-community interface.

\section{Conclusions}

There is a lack of guidance on how to facilitate research with stakeholder participation while creating educational opportunities along the lifecycle of a project. This article elaborates on the position of a transacademic interface manager (TIM), conceptualizes the task portfolio of a TIM, outlines the capacities a TIM needs to possess in order to successfully operate, and proposes an educational approach how to train students in becoming a TIM.

TIMs can play a critical role in creating high-quality transacademic learning opportunities that positively impact communities, governments, and businesses. Universities that proclaim an interest in sustainability education and real-world impact need to invest in and support TIMs in order for them to set the stage for such educational opportunities.

Efforts should be made for students and faculty to posses the capacities of a TIM as they are needed for many professional pursuits. The literature of TIM is scattered across different fields and should be integrated to establish clear career trajectories. The discourse on such career trajectories cannot remain in the academic or educational realm. A collaborative process with professional associations and organizations would be beneficial for this endeavor.

Both in terms of sustainability outcomes and sustainability education, TIM's role needs to be further understood and elaborated on, so that academic institutions consistently create the opportunities for learning and real-world impact within educational settings.

\section{Acknowledgments}

The authors would like to thank the journal Sustainability and the guest editor Ian Thomas for the invitation to contribute to this Special Issue. We also acknowledge three anonymous reviewers who provided very insightful and constructive comments on earlier versions of this article. Finally, we would like to thank our previous and current Deans, Charles Redman, Sander van der Leeuw, and 
Christopher Boone, for their continuous support to establish TIM as an organizational position in the School of Sustainability at Arizona State University.

\section{Conflicts of Interest}

The authors declare no conflict of interest.

\section{References}

1. Miller, T.R.; Wiek, A.; Sarewitz, D.; Robinson, J.; Olsson, L.; Kriebel, D.; Loorbach, D. The future of sustainability science: A solutions-oriented research agenda. Sustain. Sci. 2013, in press.

2. Wiek, A.; Ness, B.; Schweizer-Ries, P.; Brand, F.S.; Farioli, F. From complex systems analysis to transformational change: A comparative appraisal of sustainability science projects. Sustain. Sci. 2012, 7, 5-24.

3. Gladwin, T.; Kennelly J.; Krause, T. Shifting paradigms for sustainable development: Implications for management theory and research. Acad. Manage. Rev. 1995, 20, 874-907.

4. Talwar, S.; Wiek, A.; Robinson, J. User engagement in sustainability research. Sci. Public Policy 2011, 38, 379-390.

5. Lang, D.J.; Wiek, A.; Bergmann, M.; Stauffacher, M.; Martens, P.; Moll, P.; Swilling, M.; Thomas, C. Transdisciplinary research in sustainability science: Practice, principles and challenges. Sustain. Sci. 2012, 7, 25-43.

6. Brundiers, K.; Wiek, A. Educating students in real-world sustainability research: Vision and implementation. Innov. High. Educ. 2011, 36, 107-124.

7. Brundiers, K.; Wiek, A. Do we teach what we preach? An international comparison of problem- and project-based learning courses in sustainability. Sustainability 2013, 5, 1725-1746.

8. Guston, D.H. Boundary organizations in environmental policy and science: An introduction. Sci. Technol. Human Values 2001, 26, 399-408.

9. Miller, C. Hybrid management: Boundary organizations, science policy, and environmental governance in the climate regime. Sci. Technol. Human Values 2001, 26, 478-500.

10. Williams, P. The competent boundary spanner. Public Adm. 2002, 80, 103-124.

11. Funtowicz, S.O.; Ravetz, J.R. Science for the post-normal age. Futures 1993, 25, 739-755.

12. Pohl, C.; Hadorn, G.H. Principles for Designing Transdisciplinary Research; Oekom Verlag: Munich, Germany, 2006.

13. Wiek, A. Challenges of transdisciplinary research as interactive knowledge generation - experiences from transdisciplinary case study research. GAIA 2007, 16, 52-57.

14. Loorbach, D.; Rotmans, J. Managing Transitions for Sustainable Development; Springer: Berlin, Germany, 2006.

15. Loorbach, D. Transition management for sustainable development: A prescriptive, complexity-based governance framework. Governance 2010, 23, 161-183.

16. Moll, P.; Zander, U. Managing the Interface-From Knowledge to Action in Global Change and Sustainability Sciences; Oekom Verlag: Munich, Germany, 2006. 
17. Cash, D.W.; Clark, W.C.; Alcock, F.; Dickson, F.M.; Eckley, N.; Guston, D.H.; Jäger, J.; Mitchell, R.B. Knowledge systems for sustainable development. Proc. Natl. Acad. Sci. USA 2003, 100, 8086-8091.

18. Blackstock, K.L.; Kelly, G.J.; Horsey, B.L. Developing and applying a framework to evaluate participatory research for sustainability. Ecol. Econ. 2007, 60, 726-742.

19. Mushakoji, K. Peace research as internal learning process: A new meta paradigm. Int. Stud. $Q$. 1978, 22, 173-194.

20. Gibbons, M.; Limoges, C.; Nowotny, H.; Schwartzman, S.; Scott, P.; Trow, M. The New Production of Knowledge: The Dynamics of Science and Research in Contemporary Societies; SAGE: London, UK, 1994.

21. Flyvbjerg, B. Making Social Science Matter: Why Social Inquiry Fails and How it Can Succeed Again; Cambridge University Press: Cambridge, UK, 2002.

22. Robinson, J. Being undisciplined: Transgressions and intersections in academia and beyond. Futures 2008, 40, 70-86.

23. Stauffacher, M.; Walter, A.; Lang, D.; Wiek, A.; Scholz, R.W. Learning to research environmental problems from a functional socio-cultural constructivism perspective: The transdisciplinary case study approach. Int. J. Sustain. High. Educ. 2006, 7, 252-275.

24. White, D.D.; Wutich, A.; Larson, K.L.; Gober, P.; Lant, T.; Senneville, C. Credibility, salience, and legitimacy of boundary objects: Water managers' assessment of a simulation model in an immersive decision theater. Sci. Public Policy 2010, 37, 219-232.

25. Guimarães Pereira, A.; Funtowicz, S. Knowledge representation and mediation for transdisciplinary frameworks: Tools to inform. Int. J. Transdiscipl. Res. 2006, 1, 34-50.

26. Turnpenny, J.; Jones, M.; Lorenzoni, I. Where now for post-normal science? A critical review of its development, definitions, and uses. Sci. Technol. Human Values 2011, 36, 287-306.

27. Failing, L.; Gregory, R.; Harstone, M. Integrating science and local knowledge in environmental risk management: A decision-focused approach. Ecol. Econ. 2007, 64, 47-60.

28. De Vos Malan, J. Collaboration, knowledge, and the trans-disciplinary manager: Helping interdisciplinary research projects to flourish. Eur. Sci. J. 2013, 9, 19-28.

29. Wesselink, A.; Hoppe, R. If post-normal science is the solution, what is the problem?: The politics of activist environmental science. Sci. Technol. Human Values 2011, 36, 389-412.

30. Van de Kerkhof, M.; Wieczorek, A. Learning and stakeholder participation in transition processes towards sustainability: Methodological considerations. Technol. Forecast. Soc. Change 2005, 72, 733-747.

31. Walker, G.; Shove, E. Ambivalence, sustainability and the governance of socio-technical transitions. J. Environ. Policy Plan. 2007, 9, 213-225.

32. Stacey, R. Strategic Management and Organisational Dynamics: The Challenge of Complexity to Ways of Thinking about Organisations, 6th ed.; Prentice Hall: Upper Saddle River, NJ, USA, 2010.

33. Robinson, J.; Tansey, J. Co-production, emergent properties and strong interactive social research: The Georgia Basin Futures Project. Sci. Public Policy 2006, 33, 151-160.

34. Stummer, M.; Zuchi, D. Developing roles in change processes - a case study from a public sector organisation. Int. J. Proj. Manag. 2010, 28, 384-394. 
35. Stauffacher, M.; Flüeler, T.; Krütli, P.; Scholz, R.W. Analytic and dynamic approach to collaboration: A transdisciplinary case study on sustainable landscape development in a Swiss prealpine region. Syst. Pract. Action Res. 2008, 21, 409-422.

36. Van Kerkhoff, L.; Lebel, L. Linking knowledge and action for sustainable development. Annu. Rev. Environ. Resour. 2006, 31, 445-477.

37. Pielke, R., Jr. The Honest Broker: Making Sense of Science in Policy and Politics; Cambridge University Press: Cambridge, UK, 2007.

38. Scholz, R.W.; Lang, D.; Wiek, A.; Walter, A.; Stauffacher, M. Transdisciplinary case studies as a means of sustainability learning: Historical framework and theory. Int. J. Sustain. High. Educ. 2006, 7, 226-251.

39. Bernstein, M.; Wiek, A.; Brundiers, K.; Pearson, K.; Minowitz, A.; Kay, B.; Golub, A. Mitigating urban sprawl effects-A collaborative tree and shade intervention in Phoenix, Arizona, USA. Community Dev. J. 2013, submitted for publication.

40. Wiek, A.; Xiong, A.; Brundiers, K.; van der Leeuw, S. Integrating problem- and project-based learning into sustainability programs - a case study on the School of Sustainability at Arizona State University. Int. J. Sustain. High. Educ. 2013, in press.

41. Wiek, A.; Scheringer, M.; Pohl, C.; Hirsch Hadorn, G.; Valsangiacomo, A. Joint problem identification and structuring in environmental research. GAIA 2007, 16, 72-74.

42. Brundiers, K.; Wiek, A.; Redman, C.L. Real-world learning opportunities in sustainability: From classroom into the real world. Int. J. Sustain. High. Educ. 2010, 11, 308-324.

43. Bammer, G. Strengthening Interdisciplinary Research: What It Is, What It Does, How It Does It and How It Is Supported; Report for the Australian Council of Learned Academies, Melbourne, Australia. Unpublished work, 2012.

44. Wiek, A.; Lang, D.J. Transformational sustainability research-from problems to solutions. Arizona State University, Tempe, AZ, USA. Unpublished work, 2013.

45. Potvin, L.; Cargo, M.; McComber, A.M.; Delormier, T.; Macaulay, A.C. Implementing participatory intervention and research in communities: Lessons from the Kahnawake Schools Diabetes Prevention Project in Canada. Soc. Sci. Med. 2003, 56, 1295-1305.

46. Fraser, M.W.; Galinsky, M.J. Steps in intervention research: Designing and developing social programs. Res. Soc. Work Pract. 2010, 20, 459-466.

47. Segal, E.A. Social empathy: A tool to address the contradiction of working but still poor. Fam. Soc.-J. Contemp. Soc. Serv. 2007, 88, 333-337.

48. Kurucz, E.; Colbert B.; Marcus, J. Sustainability as a provocation to rethink management education: Building a progressive educative practice. Manag. Learn. 2013, doi:10.1177/1350507613506676.

49. Luks, F.; Siebenhüner, B. Transdisciplinarity for social learning? The contribution of the German socio-ecological research initiative to sustainability governance. Ecol. Econ. 2007, 63, 418-426.

50. Blackstock, K.L.; Carter, C.E. Operationalising sustainability science for a sustainability directive? Reflecting on three pilot projects. Geogr. J. 2007, 173, 343-357.

(C) 2013 by the authors; licensee MDPI, Basel, Switzerland. This article is an open access article distributed under the terms and conditions of the Creative Commons Attribution license (http://creativecommons.org/licenses/by/3.0/). 